Abstracta Iranica Abstracta Iranica

Revue bibliographique pour le domaine irano-aryen

Volume 37-38-39 | 2018

Comptes rendus des publications de 2014-2016

\title{
Ute Franke, Martina Müller-Wiener (éd.). Herat Through Time. The Collections of the Herat Museum and Archive
}

\section{Sandra Aube}

\author{
(2) OpenEdition \\ Journals \\ Édition électronique \\ URL : http://journals.openedition.org/abstractairanica/43358 \\ DOI : $10.4000 /$ abstractairanica.43358 \\ ISBN : 1961-960X \\ ISSN : 1961-960X \\ Éditeur : \\ CNRS (UMR 7528 Mondes iraniens et indiens), Éditions de l'IFRI
}

\section{Référence électronique}

Sandra Aube, «Ute Franke, Martina Müller-Wiener (éd.). Herat Through Time. The Collections of the Herat Museum and Archive ", Abstracta Iranica [En ligne], Volume 37-38-39 | 2018, document 28, mis en ligne le 30 décembre 2018, consulté le 02 octobre 2020. URL : http://journals.openedition.org/

abstractairanica/43358 ; DOI : https://doi.org/10.4000/abstractairanica.43358

Ce document a été généré automatiquement le 2 octobre 2020.

Tous droits réservés 


\title{
Ute Franke, Martina Müller-Wiener (éd.). Herat Through Time. The Collections of the Herat Museum and Archive
}

\author{
Sandra Aube
}

\section{RÉFÉRENCE}

Ute Franke, Martina Müller-Wiener (éd.). Herat Through Time. The Collections of the Herat Museum and Archive. Berlin, 2016, 732 p., 1950 phot. Coul., 250 dessins, (Ancient Herat 3), ISBN 978-3-00-051939-0

1 Ce catalogue des collections du musée national de Hérat résulte d'un projet germanoafghan dirigé par Ute Franke entre 2008 et 2012, et mené grâce au soutien du Deutsches Archäologisches Institut (DAI), puis du Museum für Islamische Kunst de Berlin. Ce projet entendait documenter la collection, tout en formant à la conservation des professionnels afghans de Hérat et Kaboul. Suite au réaménagement du musée national de Hérat dans l'actuelle citadelle Ikhtyaruddin, restaurée par l'Aga Khan Trust for Culture, le programme a également participé à la mise en place et à la valorisation de la collection au sein des nouveaux espaces, inaugurés à l'automne 2011.

2 Ce précieux catalogue, bilingue (anglais/persan), permet de découvrir enfin une partie de la très importante collection du musée national de Hérat, encore difficilement accessible en raison des conditions sécuritaires. Il fait suite et développe un premier petit catalogue du musée paru en 2008 : National Museum Herat - Areia Antiqua Through Time, ed. Ute Franke (Berlin: Deutsches Archäologisches Institut Berlin, EurasienAbteilung ; 91 p.).

3 Après une présentation du musée et de son projet de réaménagement («Showcasing History: Realisation of a Vision », Ute Franke, suivi de : « The Museum of Herat: From 
the Beginning until Present Times", Gholam Yahya Khushbeen and Homayoun Ahmadi), le présent catalogue suit une organisation chronologique. Chaque section propose une contextualisation, suivie d'un catalogue présentant succinctement les œuvres les plus significatives de la collection.

4 Les premières sections se consacrent aux périodes pré-islamiques, et remontent ainsi jusqu'au $3^{\mathrm{e}}$ millénaire, pour les œuvres les plus anciennes ( $c f$. sections « Prehistory » et "History», par Ute Franke, suivi d'une courte section sur les monnaies par Michael Alram, puis sur les seaux, par Judith A. Lerner).

5 La majeure partie du catalogue s'intéresse aux collections islamiques du musée, regroupées par matériaux. Après une section sur les verres (par Jens Kröger), puis une autre sur les métaux (par Martina Müller-Wiener), une importante part du catalogue est consacrée à la présentation des céramiques. Cette étude des céramiques s'organise selon leurs différents types : on notera notamment deux intéressants chapitres sur les pâtes argileuses des $\mathrm{X}^{\mathrm{e}}$-XIII ${ }^{\mathrm{e}}$ siècles à décor d'engobes et à décors peints à "motifs magiques» (par Ute Franke), mais également une présentation des terres cuites non glaçurées à décor moulé ou estampé (par Martina Müller-Wiener), des céramiques argileuses à glaçure monochrome (M. Müller-Wiener et U. Franke), ainsi que des pâtes siliceuses à glaçure monochrome de la fin du XII ${ }^{e}$-début du XIII siècle (U. Franke). Les décors architecturaux sont présentés à travers deux sections : une première exposant les importantes céramiques architecturales du cénotaphe de Khoja Muhammad Ghazi à Fushanj (Khorasan), daté de 780/1378 (par Claus-Peter Haase et Ute Franke); une seconde présentant divers éléments architecturaux des $\mathrm{XI}^{\mathrm{e}}-\mathrm{XIV}^{\mathrm{e}}$ siècles, en terre cuite ou en stuc (U. Franke et M. Müller-Wiener).

6 Après une présentation de la période timouride à Hérat par Claus-Peter Haase («Herat in the Timurid Period. Political History, Internal and External Relations, Economic Conditions »), la présentation des œuvres des périodes pré-moderne et moderne prend davantage la forme de varia, en trois sections : le catalogue regroupe d'abord les objets timourides et safavides des $\mathrm{XV}^{\mathrm{e}} \mathrm{XVII}{ }^{\mathrm{e}}$ siècles (M. Müller-Wiener et C.-P. Haase), puis s'intéresse aux XVI ${ }^{e}$-fin XIX ${ }^{e}$ siècles (par Christine Noelle-Karimi), avant d'aborder les objets des XVIII ${ }^{\mathrm{e}}-\mathrm{XX}^{\mathrm{e}}$ siècles (M. Müller-Wiener). Filiz Çakır Phillip signe ensuite une section consacrée aux armes de la collection.

7 Le catalogue s'achève sur les arts du livre (par C.-P. Haase) avec une présentation particulièrement intéressante des principaux manuscrits des Archives nationales de Hérat, suivis de deux chapitres sur les analyses et les questions de restauration et de conservation des manuscrits (par Ruth Keller). Cette partie était particulièrement attendue dans la mesure où ces manuscrits restent aujourd'hui encore largement inaccessibles, même pour les visiteurs du Musée national.

Ce catalogue, dense, bien illustré, offre ainsi une série de ressources aussi importantes qu'attendues pour les études sur Hérat et sa culture matérielle. Il accompagne une autre publication issue du même projet : Excavations and Explorations in Herat City. Ancient Herat 2, par Ute Franke et Thomas Urban (Berlin: Staatliche Museen zu Berlin, 2017, ISBN : 978-3-00-051937-6). 


\section{AUTEURS}

\section{SANDRA AUBE}

CNRS, Mondes iranien et indien, Paris 